\title{
Structural and Optical Properties of Ultra-high Pure Hot Water Processed $\mathrm{Ga}_{2} \mathrm{O}_{3}$ Thin Film
}

\author{
Subramani SHANMUGAN *, Devarajan MUTHARASU \\ School of Physics, Universiti Sains Malaysia (USM), 11800, Minden, Pulau Penang, Malaysia \\ cross'ref http://dx.doi.org/10.5755/j01.ms.22.2.7186
}

Received 25 May 2014; accepted 20 March 2015

\begin{abstract}
Thin film based gas sensor is an advanced application of thin film especially $\mathrm{Ga}_{2} \mathrm{O}_{3}$ (GO) thin film gas sensor is useful for high temperature gas sensor. The effect of moisture or environment on thin film properties has more influence on gas sensing properties. Radio Frequency sputtered $\mathrm{Ga}_{2} \mathrm{O}_{3}$ thin film was synthesized and processed in ultra-high pure hot water at $95{ }^{\circ} \mathrm{C}$ for different time durations. The structural properties were verified by the Xray Diffraction technique and the observed spectra revealed the formation of hydroxyl compound of Gallium (Gallium Oxide Dueterate - GOD) on the surface of the thin film and evidenced for structural defects as an effect of moisture. Decreased crystallite size and increased dislocation density was showed the crystal defects of prepared film. From the Ultra Violet - Visible spectra, decreased optical transmittance was noticed for various processing time. The formation of needle like GOD was confirmed using Field Emission Secondary Electron Microscope (FESEM) images.

Keywords: $\mathrm{Ga}_{2} \mathrm{O}_{3}$ thin film, structural properties, surface defects, optical properties, hot water process.
\end{abstract}

\section{INTRODUCTION}

In recent years resistive gas sensors based on metaloxide semiconductors have been investigated intensively, for sensing oxygen or harmful gases in a wide range of temperatures from room temperature up to $1000{ }^{\circ} \mathrm{C}[1]$. Because of toxic and short resources life of ITO, $\mathrm{ZnO}$ and $\mathrm{SnO}_{2}$ or the other materials are considered for the alternative materials to ITO [2]. Below $700^{\circ} \mathrm{C}$ gallium oxide exhibits sensitivity to reducing gases $\left(\mathrm{CO}, \mathrm{H}_{2}, \mathrm{CH}_{\mathrm{x}}\right)$ on the basis of reactions at the surface of the material [3]. $\mathrm{Ga}_{2} \mathrm{O}_{3}$ thin film has been studied as a promising dielectric material for various device applications due to its somewhat high dielectric constant $(10-14)$ and large band gap $(\sim 5 \mathrm{eV}) . \quad \mathrm{Ga}_{2} \mathrm{O}_{3}$ thin films have been used in luminescent phosphors, high temperature sensors, deepUV transparent oxides and dielectric coatings for solar cells $[4-6]$.

$\mathrm{Ga}_{2} \mathrm{O}_{3}$ material has high potential to be a new generation of optoelectronic devices applied as transparent conductive oxide [7]. The conductivity of $\mathrm{Ga}_{2} \mathrm{O}_{3}$ material depends on the atmospheric condition so that it is suitable for gas sensor application [8]. It is also possible that there is predominant effect of surrounding environment on the device due to chemical reactions. After coating of $\mathrm{Ga}_{2} \mathrm{O}_{3}$ thin film, no report has been published about the further oxidation behavior in moisture based environment. Hot water oxidation has already used to oxidize solid uranium metal [9]. The hot water process will also affect the physical properties of the thin film material as a result of hydrothermal treatment. Qiu et al. [10] have discovered and reported on the synthesis of crystalline $\mathrm{ZnO}$ film by direct reaction of ultra-high pure water and metallic $\mathrm{Zn}$ film. Our group has also studied the influence of ultra-high pure hot water on the properties of various oxide thin films

\footnotetext{
* Corresponding author. Tel.: +60-46533672; fax: +60-46799150.

E-mail address: subashanmugan@gmail.com (S. Shanmugan)
}

[11-13]. For gas sensing application, the surface of thin film is very important and should be analyzed.

Normally, $\mathrm{Ga}_{2} \mathrm{O}_{3}$ thin film prepared by sputtering using different targets showed more oxygen deficiency [14]. An amorphous $\mathrm{Ga}_{2} \mathrm{O}_{3}$ thin film may be utilized as a good gas sensor with oxygen deficiency [15]. Annealing or processing environment was influenced the surface structure of $\beta-\mathrm{Ga}_{2} \mathrm{O}_{3}$ nanostructure. Jangir et. al., reported the photoluminescence of $\beta-\mathrm{Ga}_{2} \mathrm{O}_{3}$ nano structure in moist environment especially at $800{ }^{\circ} \mathrm{C}$ using $\mathrm{N}_{2}$ gas as carrier gas [16]. There are no reports on the influence of hot moister on $\mathrm{Ga}_{2} \mathrm{O}_{3}$ thin films.

In order to understand more, it is necessary to study the influence of hot moisture condition or hot water for various process times on the properties of $\mathrm{Ga}_{2} \mathrm{O}_{3}$ thin film surface at moderate temperature. In this study, the prepared $\mathrm{Ga}_{2} \mathrm{O}_{3}$ thin film is processed in ultra-high pure hot water for different time durations and reported their structural and optical properties.

\section{EXPERIMENTAL DETAILS}

\section{1. $\mathrm{Ga}_{2} \mathrm{O}_{3}$ thin film synthesis}

$\mathrm{Ga}_{2} \mathrm{O}_{3}$ thin film were deposited using pure $\mathrm{Ga}_{2} \mathrm{O}_{3}$ (99.99\% purity) target ( 3 inch in diameter and $4 \mathrm{~mm}$ in thickness) on commercial glass substrates by RF sputtering (Edwards make, Model-Auto 500) at room temperature. The chamber was initially evacuated to high vacuum of $7.2 \times 10^{-6}$ mbar and fixed as base pressure. High pure $\mathrm{Ar}$ $(99.999 \%)$ was used as sputtering gas. The substrates were cleaned ultrasonically by rinsing in acetone bath and isopropyl alcohol. The cleaned substrates were loaded into the chamber and evacuated the chamber to reach the vacuum of $8.5 \times 10^{-6}$ mbar. In order to remove the surface oxidation of the target, pre-sputtering was carried out for 5 min before starting deposition at Ar pressure of $3.2 \times 10^{-3}$. Substrate to target distance of $7 \mathrm{~cm}$ was kept constant for all depositions. All coatings were made in $200 \mathrm{~W} \mathrm{RF}$ 
power at chamber pressure of $8.2 \times 10^{-3}$ mbar. The coating was continued up to $2 \mathrm{~h}$ and the thickness of samples was measured by optical method as $125 \mathrm{~nm}$. To get the uniform thickness, rotary drive system was used and 25 RPM was fixed.

\subsection{Ultrahigh pure water treatment and characterization}

Ultra-high pure hot water (resistivity more than $18.2 \mathrm{M} \Omega \mathrm{cm}$ ) treatment of $\mathrm{Ga}_{2} \mathrm{O}_{3}$ thin film was performed at $95{ }^{\circ} \mathrm{C}$, in a magnetic stirrer. The hot water treatment was performed at four different times $(1 \mathrm{~h}, 2 \mathrm{~h}, 3 \mathrm{~h}$ and $4 \mathrm{~h})$. The crystalline nature of the $\mathrm{Ga}_{2} \mathrm{O}_{3}$ thin films was investigated by using a high resolution X-ray diffraction (HRXRD, X'pert-PRO, Philips, Netherlands) technique. A $\mathrm{Cu} \mathrm{K} \alpha(k=1.54056 \AA)$ source was used, and the scanning range was between $2 \theta=20^{\circ}$ and $80^{\circ}$. The transmittance of processed samples was measured in the visible range using Shimadzu UV-1800 UV/Vis/NIR scanning spectrophotometer (Shimadzu). The transmittance was automatically calibrated against that of a bare glass substrate as a reference sample, and the refractive index and extinction coefficient were obtained from the transmittance curve. PL and Raman spectra of the samples were also measured at room temperature by Jobin Yvon HR $800 \mathrm{UV}$ using $325 \mathrm{~nm}$ lines of a He-Cd laser and Ar laser as the excitation source respectively. The surface morphology of the processed $\mathrm{Ga}_{2} \mathrm{O}_{3}$ thin film was also tested using Field Emission Scanning Electron Microscope (FESEM) (Nova NanoSEM 450). New paragraph must be indented in the first line by $0.6 \mathrm{~cm}$.

\section{RESULTS AND DISCUSSION}

\subsection{Structural properties}

The crystalline qualities of the $\mathrm{Ga}_{2} \mathrm{O}_{3}$ thin films for different processing time were evaluated using XRD spectra and the observed results are given in Fig. 1. It includes the XRD spectrum of as grown $\mathrm{Ga}_{2} \mathrm{O}_{3}$ thin film by RF sputtering. All the XRD peaks have been indexed thereby confirming the formation of $\beta-\mathrm{Ga}_{2} \mathrm{O}_{3}$ monoclinic structure (JCPDS Card No. 760573) along with gallium oxide deuterate (JCPDS Card No. 700537). In ultra-high pure hot water treatment, there may be a contact between the thin film surface and water molecule. In general, water vapor or water molecules react with the metal oxides in two ways. At low temperatures, water is adsorbed (ads) in its molecular form according to the following equation:

$\mathrm{H}_{2} \mathrm{O}_{\text {gas }} \rightarrow \mathrm{H}_{2} \mathrm{O}_{\text {ads }} \rightarrow \mathrm{H}_{2} \mathrm{O}_{\text {ads }}^{\cdot}+\mathrm{e}^{-}$.

At high temperatures $\left(780^{\circ} \mathrm{C}\right.$ and above), the adsorption of $\mathrm{OH}$ group dominates according to the following equation [17]:

$\mathrm{H}_{2} \mathrm{O}_{\text {ads }}+\mathrm{O}_{0}^{\mathrm{x}} \rightarrow 2 \mathrm{OH}$

$\mathrm{OH}+\mathrm{e}^{-} \rightarrow \mathrm{OH}^{-}$.

The dominating mechanism is adsorption of the $\mathrm{OH}$ groups according to Eq. 2 a, b. In our hot water process, the $\mathrm{OH}$ groups are adsorbing on the surface of $\mathrm{Ga}_{2} \mathrm{O}_{3}$ thin film and forming the gallium oxide deuterate as trace basis which is already confirmed by observing a strong peak nearly at $\sim 2 \theta=21^{\circ}$ in XRD spectra (see Fig. 1).

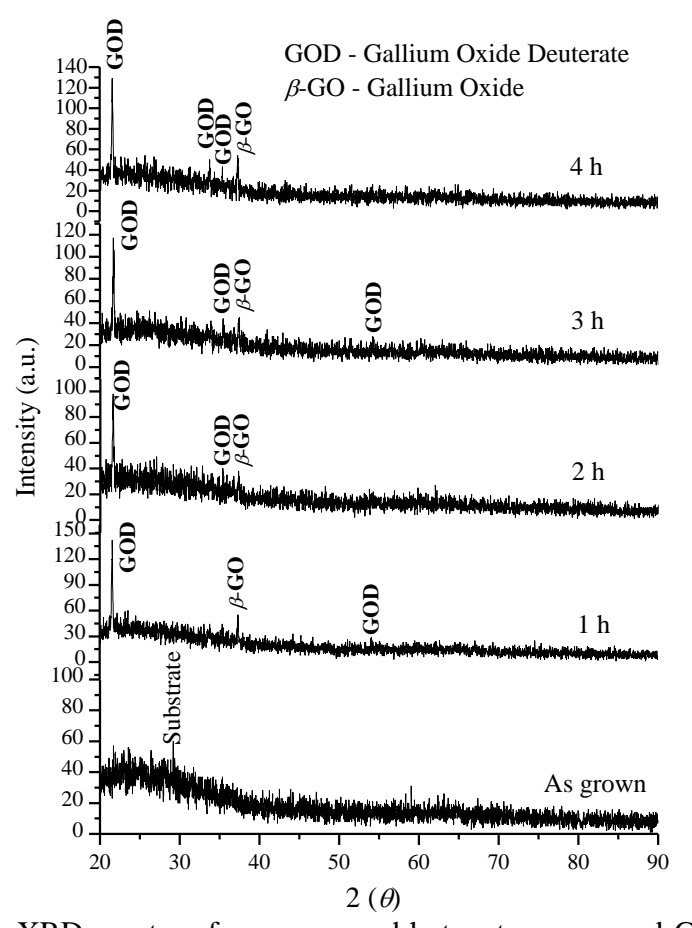

Fig. 1. XRD spectra of as grown and hot water processed $\mathrm{Ga}_{2} \mathrm{O}_{3}$ thin film for various process times

The XRD spectra show that the as-grown sample shows amorphous nature $[5,10]$ and improved crystallinity after processing in ultra-high pure hot water at $95^{\circ} \mathrm{C}$. Fig. 1 also shows that the (401) oriented $\beta$ - $\mathrm{Ga}_{2} \mathrm{O}_{3}$ phase could be observed for all hot water processed samples along with a predominant peak at $2 \theta \sim 21.55$ which is related to (110) oriented gallium oxide deuterate (GOD). Because of the reaction of $\mathrm{OH}$ group at the surface of the thin film, it is expected to form $\mathrm{GaO}_{\mathrm{x}}$ group which creates surface states as defects [16]. This is the indication of surface defects as a result of hot water process. From Fig. 1, the amorphous nature of the sample could be revealed for all samples and this amorphous nature could bring desired insulating property for the thin films [18].

The observed structural parameters are summarized in Table 1. From the Table 1, the observed intensity is low for the samples processed at $2 \mathrm{~h}$ duration and increases gradually with processing time increases. From the XRD spectra, the crystallite size of (401) oriented peak of $\beta$ $\mathrm{Ga}_{2} \mathrm{O}_{3}$ thin film is calculated using Debey-Scherrer formula [19]:

$D=0.94 \lambda / \beta \cos \theta$,

where $\lambda$ is wavelength (in Angstrom), $\beta$ is the broadening of diffraction peak (in radians), $\theta$ is the Bragg diffraction angle and plotted against processing time in Fig. 2. It shows that the crystallite size decreases as processing time increases.

The dislocation density is mainly based on the crystallite size and hence it differs as a result of change in crystallite size. Dislocation density is one among the structural defects parameters and defined as the length of dislocation lines per unit volume of crystal, was evaluated from the following relation [20]:

$\delta=1 / D^{2}$

and the data are plotted as shown in Fig. 2 (inset). 
Table 1. Structural properties of hot water processed $\mathrm{Ga}_{2} \mathrm{O}_{3}$ thin film

\begin{tabular}{|c|c|c|c|c|c|c|c|}
\hline Obs., 2-Theta ${ }^{\circ}$ & Std., 2-Theta ${ }^{\circ}$ & $d$ (Obs.), $\AA$ & $d$ (Std.), $\AA$ & FWHM, 2-Theta ${ }^{\circ}$ & hkl & JCPDS card No. & Compound \\
\hline \multicolumn{8}{|c|}{$1 \mathrm{~h}$} \\
\hline 21.561 & 21.66 & 4.11822 & 4.099 & 0.114 & 110 & 700537 & GOD \\
\hline 37.329 & 37.38 & 2.40697 & 2.403 & 0.082 & 401 & 760573 & GO \\
\hline 54.183 & 54.36 & 1.69144 & 1.686 & 0.100 & 221 & 700537 & GOD \\
\hline \multicolumn{8}{|c|}{$2 \mathrm{~h}$} \\
\hline 21.604 & 21.66 & 4.11005 & 4.099 & 0.111 & 110 & 700537 & GOD \\
\hline 35.375 & 35.37 & 2.53533 & 2.536 & 0.088 & 021 & 700537 & GOD \\
\hline 37.346 & 37.38 & 2.40594 & 2.403 & 0.079 & 401 & 760573 & GO \\
\hline \multicolumn{8}{|c|}{$3 \mathrm{~h}$} \\
\hline 21.674 & 21.66 & 4.09696 & 4.099 & 0.126 & 110 & 700537 & GOD \\
\hline 35.428 & 35.37 & 2.5317 & 2.536 & 0.023 & 021 & 700537 & GOD \\
\hline 37.488 & 37.38 & 2.39715 & 2.403 & 0.094 & 401 & 760573 & $\mathrm{GO}$ \\
\hline 54.21 & 54.36 & 1.69065 & 1.686 & 0.113 & 221 & 700537 & GOD \\
\hline \multicolumn{8}{|c|}{$4 \mathrm{~h}$} \\
\hline 21.578 & 21.66 & 4.115 & 4.099 & 0.153 & 110 & 700537 & GOD \\
\hline 33.784 & 33.88 & 2.65098 & 2.643 & 0.066 & 130 & 700537 & GOD \\
\hline 35.428 & 35.37 & 2.5317 & 2.536 & 0.023 & 021 & 700537 & GOD \\
\hline 37.301 & 37.38 & 2.40871 & 2.403 & 0.162 & 401 & 760573 & GO \\
\hline
\end{tabular}

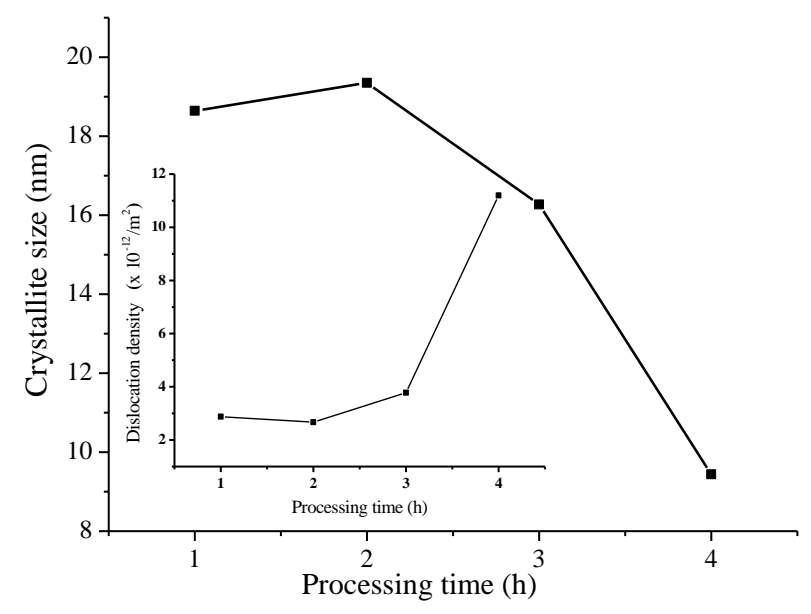

Fig. 2. Variation in crystallite size and dislocation density of hot water processed $\mathrm{Ga}_{2} \mathrm{O}_{3}$ thin film for various time durations

According to the equation, the crystallite size of the film decides the dislocation density and increases with processing time increases.

\subsection{FESEM analysis}

In order to confirm, the surface image of hot water processed $\mathrm{Ga}_{2} \mathrm{O}_{3}$ thin film treated at 4 hours duration was captured using FESEM as shown in Fig. $3 \mathrm{a}-$ b. Since the images of all other samples processed at different time duration has similar structure as shown in Fig. $3 \mathrm{~b}$, the image of samples processed at $4 \mathrm{~h}$ duration is presented and taken for consideration for discussion. Fig. 3 a shows the surface image of as grown $\mathrm{Ga}_{2} \mathrm{O}_{3}$ thin film and shows that the uniform surface with uniform size of the particles (Fig. 3 a). It clearly indicates that the needle like Gallium Oxide Dueterate is spread over on the surface of $\mathrm{Ga}_{2} \mathrm{O}_{3}$ thin film after processing (Fig. 3 b). Fig. 3 clearly distinguishes the processed and unprocessed $\mathrm{Ga}_{2} \mathrm{O}_{3}$ thin film and the cracks were also observed on the surface of thin film in the processed thin film.

\subsection{Optical studies}

The UV spectra of as-grown and ultra-high pure hot water processed thin film samples are given in Fig. 4.

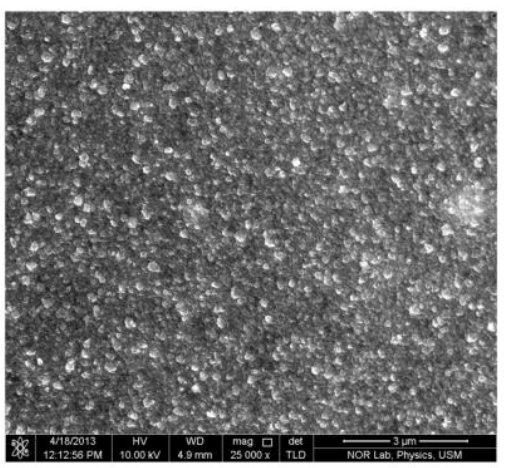

a

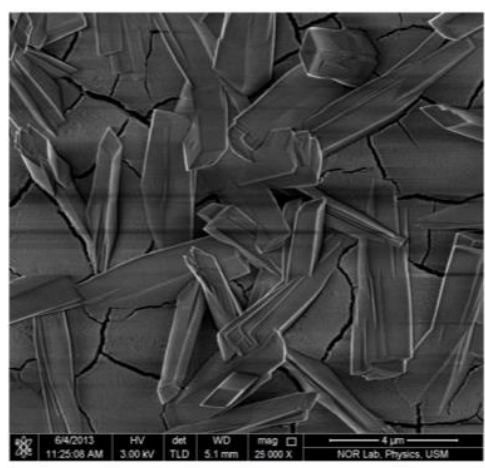

b

Fig. 3. FESEM images of: $a$ - as grown; $b$ - hot water processed $\mathrm{Ga}_{2} \mathrm{O}_{3}$ thin film at $4 \mathrm{~h}$ duration in ultra-high pure media

It shows that the as grown samples show higher transmittance value than processed samples. Moreover, the oscillating behavior of transmittance spectra reveals the uniform thickness of the film.

Fig. 4 also depicts that the high transmittance value could be observed for all processed samples in the UV region than visible and IR region. Among the processed samples, the $\mathrm{Ga}_{2} \mathrm{O}_{3}$ sample processed at $2 \mathrm{~h}$ duration shows higher transmittance than other samples. Low value in transmittance could also be observed for the samples processed at $3 \mathrm{~h}$ duration and the oscillating behavior of 
the curve for these samples is also reduced.

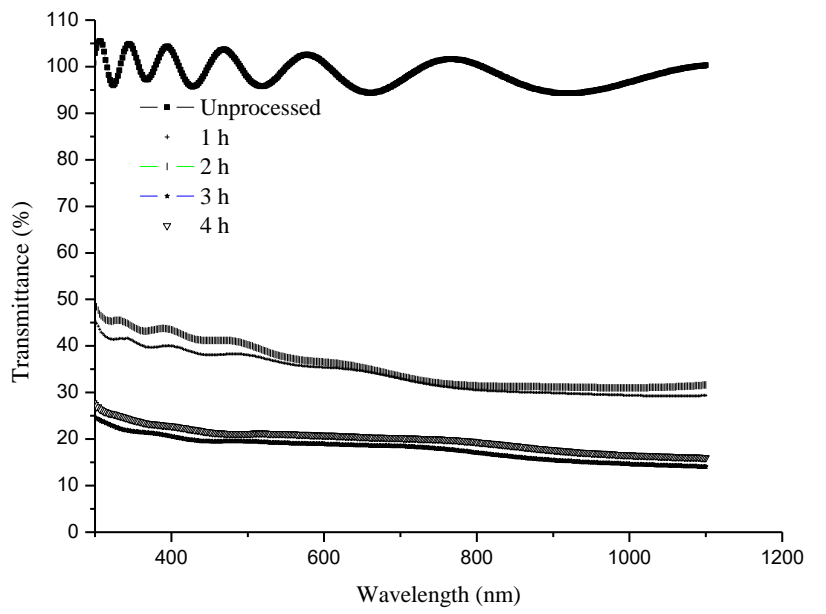

Fig. 4. Transmittance spectra of as grown and hot water processed $\mathrm{Ga}_{2} \mathrm{O}_{3}$ thin film at various processing times in ultra-high pure media

\section{CONCLUSIONS}

RF sputtered $\mathrm{Ga}_{2} \mathrm{O}_{3}$ thin film was synthesized on glass substrates and post processed with ultra-high pure hot water for various process times. XRD spectra revealed the formation of highly intensive peak of $\mathrm{Ga}_{2} \mathrm{O}_{3}$ phase and Gallium Oxide Deuterate phase and exhibited the effect of hot water process. Decreased crystallite size was noticed with $4 \mathrm{~h}$ hot water processed samples. The optical properties also evidenced the formation of defects as reduced transmittance for the effect of ultra-high pure hot water treatment. Overall, it is suggested that the formation of hydroxyl group on the surface of $\mathrm{Ga}_{2} \mathrm{O}_{3}$ thin film sensor is possible when it operates at high temperature in presence of moisture environment.

\section{REFERENCES}

1. Meixner, H., Lampe, U. Metal oxide sensors Sensors and Actuators B 33 1996: pp. 198-202. http://dx.doi.org/10.1016/0925-4005(96)80098-0

2. Hosono, H. Recent progress in transparent oxide semiconductors: Materials and device application Thin Solid Film 515 (15) 2007: pp. 6000-6014.

3. Fleischer, M., Meixner, H. Sensing reducing gases at high temperatures using long-term stable $\mathrm{Ga}_{2} \mathrm{O}_{3}$ thin films Sensors and Actuators B $6(1-3) \quad 1992$ : pp. 257-261.

4. Fleischer, M., Hanrieder, W., Meixner, H. Stability of semiconducting gallium oxide thin films Thin Solid Films 190 (1) 1990: pp. $93-102$.

http://dx.doi.org/10.1016/0040-6090(90)90132-W

5. Orita, M., Ohta, H., Hirano, M., Hosono, H. Deep Ultraviolet Transparent Conductive $\beta-\mathrm{Ga}_{2} \mathrm{O}_{3}$ Thin Films Applied Physics Letter 77 (25) 2000: pp. 4166-4168. http://dx.doi.org/10.1063/1.1330559

6. Shan, F. K, Liu, G. X., Lee, W. J., Lee, G. H, Kim, I. S., Shin, B. C. Structural, electrical, and optical properties of transparent gallium oxide thin films grown by plasmaenhanced atomic layer deposition Journal of Applied Physics 98 (2) 2005: pp. 023504-023504-6.
7. Hosono, H., Ohta, H., Orita, M., Ueda, K., Hirani, M. Frontier of transparent conductive oxide thin films Vacuum 66 2002: pp. 419-425. http://dx.doi.org/10.1016/S0042-207X(02)00165-3

8. Hoefer, U., Frank, J., Fleisher, M. High temperature $\mathrm{Ga}_{2} \mathrm{O}_{3}$-gas sensors and $\mathrm{SnO}_{2}$-gas sensors: a comparison Sensors Actuators B 78 (1-3) 2001: pp. 6-11.

9. Delegard, C. H., $\quad$ Sinkov, S. I., $\quad$ Schmidt, A. J., Daniel, R. C., Burns. C. A. A report on "Effect of Time, Heat and Oxygen on K Basin Sludge Agglomeration, Strength and Solids Volume". PNNL-20100, 53451-RPT13 Pacific Northwest National Laboratory, Richland, Washington, January 2011.

10. Qiu, Z., Nadamura, Y., Ishiguro, T. Formation of zinc oxide film by boiling metallic zinc film in ultrapure water Thin Solid Films $518(21)$ 2010: pp. 5912-5915. http://dx.doi.org/10.1016/j.tsf.2010.05.077

11. Shanmugan, S., Mutharasu, D., Formation of copper oxide thin films from $\mathrm{rf}$ sputtered $\mathrm{Cu}$ thin film by boiled ultra-high pure water IEEE Proceedings, IEEE-ICSE 2012 2012: pp. 145-149.

12. Shanmugan, S., Mutharasu, D. Optical properties of amorphous $\mathrm{ZnO}$ thin film prepared from boiled $\mathrm{Zn}$ thin film in ultra-high pure water European Physical Journal: Applied Physics 58 2012: pp. 30301-30301-7.

13. Shanmugan, S., Mutharasu, D. Synthesis of $\mathrm{In}_{2} \mathrm{O}_{3}$ thin films from indium thin film by hot water oxidation method Metallurgical Material Transaction A 43 (1) 2012: pp. 6-9. http://dx.doi.org/10.1007/s11661-011-1016-1

14. Ogita, M., Higo, K., Nakanishi, Y., Hatanaka, Y. $\mathrm{Ga}_{2} \mathrm{O}_{3}$ thin film for oxygen sensor at high temperature Applied Surface Science 175-176 2001: pp. 721-725.

15. Nanto, H., Mi-nami, T., Takata, S. Zinc-oxide thin-film ammonia gas sensors with high sensitivity and excellent selectivity Journal of Applied Physics 60 (2) 1986: pp. $482-484$. http://dx.doi.org/10.1063/1.337435

16. Jangir, R., Porwal, S., Pragya, T., Puspen, M., Rai, S. K., Tapas, G., Oak, S. M., Deb, S. K. Photoluminescence study of $\beta-\mathrm{Ga}_{2} \mathrm{O}_{3}$ nanostructures annealed in different environments Journal of Applied Physics 112(3) 2012: pp. $034307-034307-6$.

17. Giber, J., Perczel, I. V., Gerblinger, J., Lampe, U., Fleischer, M. Coadsorption and cross sensitivity on high temperature semiconducting metal oxides: water effect on the coadsorption process Sensors and Actuators B 18-19 1994: pp. 113-118.

18. Liu, G. X., Shan, F. K., Park, J. J., Lee, W. J., Lee, G. H., Kim, I. S., Shin, B. C., Yoon, S. G. Electrical properties of $\mathrm{Ga}_{2} \mathrm{O}_{3}$-based dielectric thin films prepared by plasma enhanced atomic layer deposition (PEALD) Journal of Electroceramics 17 2006: pp. 145-149. http://dx.doi.org/10.1007/s10832-006-0461-5

19. Gordillo, G., Flórez, J. M., Hernández, L. C. Preparation and characterization of CdTe thin films deposited by CSS Solar Energy Materials and Solar Cells 37 (3-4) 1995: pp. 273-281.

20. Stokes, A. R., Wilson, A. C. J. The diffraction of X-rays by distorted crystal aggregates - I Proceedings of the Physical Society 56 1944: pp. 174-181. http://dx.doi.org/10.1088/0959-5309/56/3/303 